Research Article

\title{
Microstructure and Texture Evolution of Aluminum in the Al-Nb/ Ti/Ni Composite Fabricated by the ARB Process
}

\author{
Nan Ye (i) and Xueping Ren (iD \\ School of Materials Science and Engineering, University of Science and Technology Beijing, Beijing 100083, China \\ Correspondence should be addressed to Xueping Ren; rxp33@ustb.edu.cn
}

Received 5 June 2020; Revised 1 July 2020; Accepted 7 July 2020; Published 27 July 2020

Guest Editor: Tifeng Jiao

Copyright (๑) 2020 Nan Ye and Xueping Ren. This is an open access article distributed under the Creative Commons Attribution License, which permits unrestricted use, distribution, and reproduction in any medium, provided the original work is properly cited.

\begin{abstract}
The Al-Nb/Ti/Ni composite was fabricated from pure $\mathrm{Al}, \mathrm{Ni}$, Ti, and $\mathrm{Nb}$ sheets by the ARB technology. The microstructure evolution was observed by scanning electron microscopy, $\mathrm{x}$-ray diffraction, and transmission electron microscopy. The evolution was evaluated by the electron backscattered diffraction (EBSD) technique. A couple of results we obtained showed that the microstructure of $\mathrm{Al}$ changed from equiaxed grains to a lamellar structure, and the grain size in the ND decreased gradually. Finally, the average grain size in the ND was $0.31 \mu \mathrm{m}$. Additionally, the fraction of HAGBs increased after the third pass, resulting from the dynamic recovery and the shear bands. The texture evolution was tested by electron backscattered diffraction. After the fourth pass, the $\mathrm{Al}$ exhibited a combination texture of rolling texture and shear texture. The rolling texture components were composed of Copper $\{112\}<111>$, Dillamore $\left\{\begin{array}{lll}4 & 41\end{array}\right\}<11118>, S\{123\}<634>$, and Brass $\{011\}<211>$, and the shear texture components were Rotated Cube $\{001\}<110>$ and $\{111\} / / \mathrm{ND}$. The microhardness of $\mathrm{Ni}, \mathrm{Ti}, \mathrm{Nb}$, and $\mathrm{Al}$ was improved in the ARB process and finally reached $226.4,246.3,187.2$, and $44.2 \mathrm{HV}$, respectively.
\end{abstract}

\section{Introduction}

Metal matrix composites (MMC) combine the advantages of each component and makes up for the shortcomings, which has excellent comprehensive properties that cannot be matched by a single metal or alloy so that it becomes a focus in materials science today. Metal matrix composites are prepared by the bonding technology to achieve metallurgical bonding between two or more metals with different characteristics. [1-5].

At present, the major methods of producing metal composites are casting, powder metallurgy, spray deposition, etc. However, most of these technologies require expensive equipment and complex processes, limiting their industrial application [6-10]. The accumulative roll bonding (ARB) technology is a kind of severe plastic deformation (SPD) process which can fabricate bulk composites continuously and has a good potential for industrialization. Compared with other SPD processes, ARB technology, it can produce not only ultrafine grained metals but also metal matrix composites.

Aluminum is generally used as a matrix for metal matrix composites due to its lightweight and good formability. Recently, a number of researchers have reported the Almatrix composite produced by the ARB process, such as Al$\mathrm{Ti}$ [11], Al-Cu [12], Al-Ni [13, 14], Al-Mg [15-17], Al-Mg-Ti [18], Al-Ti-Nb [19], Al-Cu-Ni [20], Al-Cu-Sn [21], and Al$\mathrm{Cu}-\mathrm{Zn}$ [22]. However, the research about multimetal composites fabricated by the ARB process is insufficient. Titanium aluminum alloys are widely used in the automobile and aviation industries due to its low density-high strength, excellent corrosion resistance, and high-temperature performance. Adding nickel to the titanium aluminum alloy can improve its corrosion resistance, and adding niobium can enhance its high-temperature performance $[19,23]$. Therefore, the Al-Nb/Ti/Ni composite will have excellent comprehensive properties. Metal sheets are arranged in a symmetrical form in order to ensure the stability of the 
composites. Aluminum sheets located on the surface and in the middle can improve the feasibility of the ARB process. Therefore, the metal sheets were stacked in the order of $\mathrm{Al} /$ $\mathrm{Ni} / \mathrm{Ti} / \mathrm{Al} / \mathrm{Nb} / \mathrm{Al} / \mathrm{Ti} / \mathrm{Ni} / \mathrm{Al}$.

Texture analysis is a very critical means to explore the grain oriental of metals during plastic deformation so that we can more clearly understand the changes in the microstructure of the material. Existing researches have focused on the texture evolution of single metals or alloys [24-31] prepared by the ARB technology. However, the investigation on the texture of multimetal composites is insufficient.

In previous studies, we have prepared $\mathrm{Ni}-\mathrm{Ti}-\mathrm{Al}-\mathrm{Cu}$ composites and investigated their microstructure evolution and mechanical properties. We will pay more attention to the texture evolution of the $\mathrm{Al}-\mathrm{Nb} / \mathrm{Ti} / \mathrm{Ni}$ composite in this work. The EBSD technology was used to investigate the texture evolution of the $\mathrm{Al}-\mathrm{Nb} / \mathrm{Ti} / \mathrm{Ni}$ composite.

\section{Experimental Procedures}

The chemical compositions and dimensions of raw sheets (pure aluminum, nickel, titanium, and niobium) are depicted in Table 1.

$\mathrm{Al}, \mathrm{Ni}, \mathrm{Ti}$, and $\mathrm{Nb}$ sheets with a thickness of $0.2 \mathrm{~mm}$ were annealed, respectively, at $623 \mathrm{~K}, 1073 \mathrm{~K}, 1073 \mathrm{~K}$, and $1473 \mathrm{~K}$, for 30 minutes. The surface of the metals needed to be polished with a steel brush due to the oxides formed during the annealing process and then degreased in alcohol and acetone. Four aluminum sheets, two nickel sheets, two titanium sheets, and one niobium sheet were stacked (as depicted in Figure 1). The stacked sheets were fastened by steel wires at the four corners to keep stability.

The rolling process was conducted on a two-high mill with a $50 \%$ reduction at room temperature. The diameter of the roller was $350 \mathrm{~mm}$, and the rolling speed was $10 \mathrm{rpm}$. The bonded samples were cut into two, degreased, and brushed. The samples were stacked and continued to roll with a target of $50 \%$ reduction. The experiment procedure was repeated for four times without lubrication. The Al-Nb/Ti/Ni composite was fabricated successfully after four passes accumulative roll bonding process. The Von Mises equivalent strains for each pass of the ARB process are 0.8, 1.6, 2.4, and 3.2 , respectively. The complete accumulative roll bonding process is illustrated in Figure 1.

Microstructure evolution of the $\mathrm{Al}-\mathrm{Nb} / \mathrm{Ti} / \mathrm{Ni}$ composite was observed by scanning electron microscopy (SEM, JSM7001F) and transmission electron microscopy (TEM, JEM2010, $200 \mathrm{kV}$ ). The texture evolution of the Al layer in the ARB process was analyzed using an electron backscattered diffraction (EBSD) technique, and the EBSD test was conducted at a scanning electron microscopy (SEM, JSM-7001F) equipped with a TSL-OIM EBSD analysis system. The EBSD measurements were performed at a voltage of $20 \mathrm{kV}$, a tilt angle of $70^{\circ}$, a magnification of 2500 , and a scan step size of 0.06 microns. The EBSD samples were electropolished in an ethanol and perchloric acid (5 vol.\%) solution at $20 \mathrm{~V}$ for $20 \sim 30 \mathrm{~s}$. The microhardnesses (HV) of
TABLE 1: Chemical composition and dimensions of the used sheets.

\begin{tabular}{lcc}
\hline & Chemical composition (wt\%) & $\begin{array}{c}\text { Dimension } \\
(\mathrm{mm} \times \mathrm{mm} \times \mathrm{mm})\end{array}$ \\
\hline $\mathrm{Al}$ & $0.05 \mathrm{Cu}, 0.25 \mathrm{Si}, 0.35 \mathrm{Fe} 0.03 \mathrm{Mg}, \mathrm{Al}$ bal & $100 \times 50 \times 0.2$ \\
$\mathrm{Ni}$ & $0.01 \mathrm{Fe}, 0.01 \mathrm{Si}, 0.03 \mathrm{Mn}, \mathrm{Ni}$ bal & $100 \times 50 \times 0.2$ \\
$\mathrm{Ti}$ & $0.4 \mathrm{Si}, 0.4 \mathrm{Fe}, 0.04 \mathrm{Zn}, \mathrm{Ti}$ bal & $100 \times 50 \times 0.2$ \\
$\mathrm{Nb}$ & $0.03 \mathrm{Mn}, 0.01 \mathrm{Fe}, 0.01 \mathrm{Si}, \mathrm{Nb}$ bal & $100 \times 50 \times 0.2$ \\
\hline
\end{tabular}

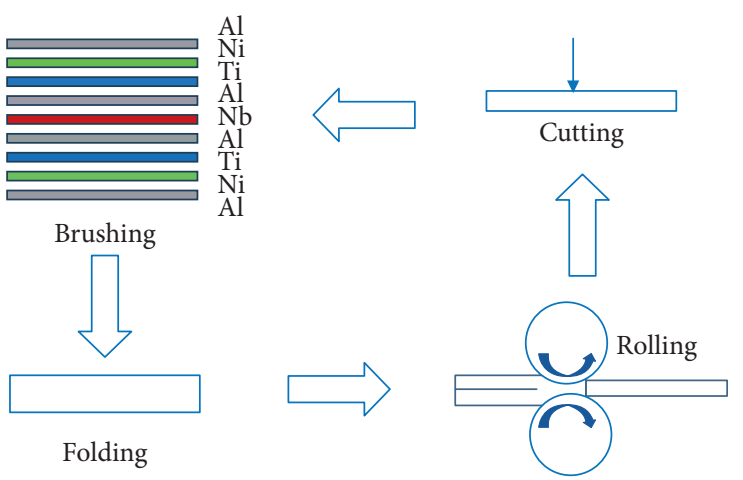

FIgURE 1: Schematic illustration of the accumulative roll bonding process.

the composites were measured by a hardness tester at a load of $50 \mathrm{~g}$ for $10 \mathrm{~s}$.

\section{Result and Discussion}

3.1. Microstructures. Figure 2 is the SEM image of the Al$\mathrm{Nb} / \mathrm{Ti} / \mathrm{Ni}$ composite on the RD-ND plane. The microstructural evolution of various layers of the $\mathrm{Al}-\mathrm{Nb} / \mathrm{Ti} / \mathrm{Ni}$ composite after the different passes $(1,2,3$, and 4$)$ is demonstrated in Figure 2. A good bonding between individual layers could be observed in Figure 2(a). The size of nickel, titanium, and niobium decreased with the further deformation, and the thickness of the niobium fragments was visibly smaller than that of $\mathrm{Ni}$ and $\mathrm{Ti}$ due to the smaller deformation resistance. In Figure 2(d), Nb fragments with extremely small size could be observed.

In the first pass, the composite material also exhibited a layered structure with the locally uneven deformation. Obvious neckings and fractures appeared in $\mathrm{Ti}, \mathrm{Ni}$, and $\mathrm{Nb}$ layers when the ARB pass increased. A couple of investigations $[18,19]$ reported similar results. The plastic instability occurred because of the different mechanical properties of individual layers, and then nenckings eventually breaking were visible in the hard phase. Since the metals $\mathrm{Ni}, \mathrm{Ti}$, and $\mathrm{Nb}$ are hard phases relative to the matrix $\mathrm{Al}$, then the $\mathrm{Ti}, \mathrm{Ni}$, and $\mathrm{Nb}$ layers necked and fractured with the further deformation. In the fourth pass, the metal fragments (nickel, titanium, and niobium) were homogeneously distributed in the multimetal composite.

Another reason for the formation of metal fragments was that the reinforcements (nickel, titanium, and niobium) were cut by the shear band during the plastic deformation process, and finally, the metal fragments are 


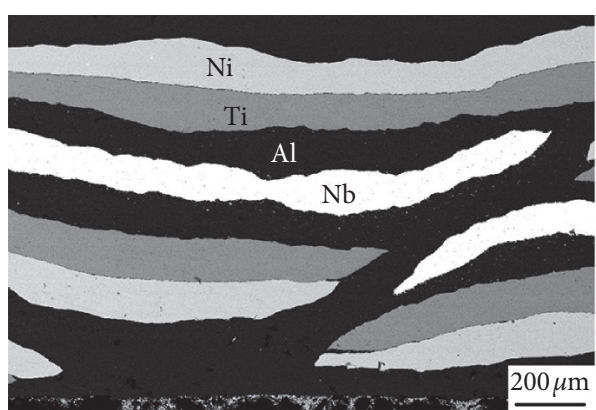

(a)

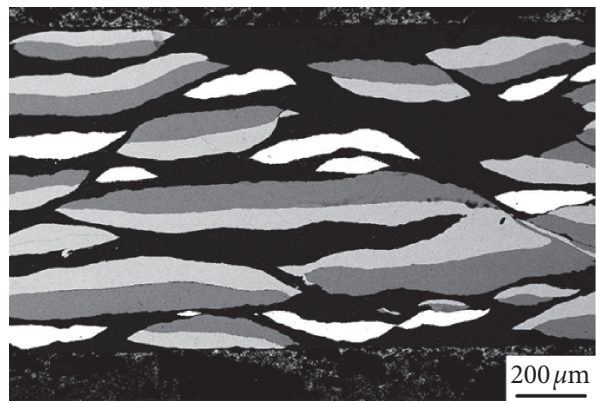

(c)

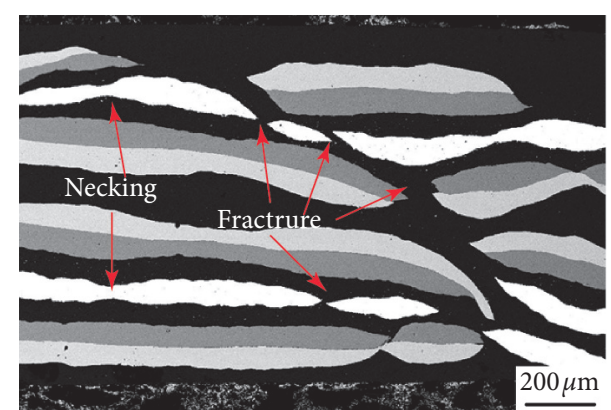

(b)

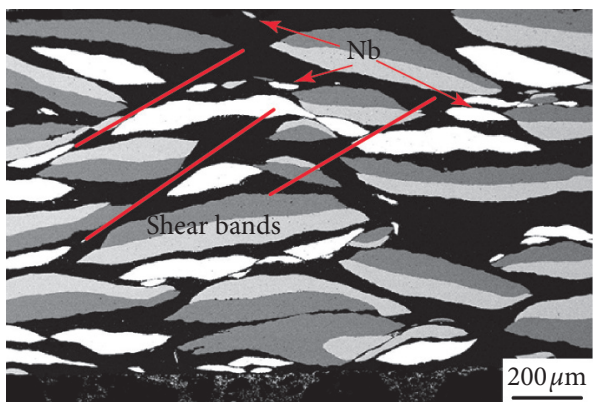

(d)

FIGURE 2: SEM micrographs on the RD-ND plane of the Al-Nb/Ti/Ni composites: (a) 1st pass, (b) 2nd pass, (c) 3rd pass, and (d) 4th pass.

formed. In Figure 2(d), we could observe that there were shear bands in the matrix. The shear bands were at an angle to the RD and the angle was generally about $30^{\circ}-45^{\circ}$. Because of the different mechanical properties of the four metals, a shear band was generated with the effect of shear forces [18]. At last, the reinforcements $(\mathrm{Ni}, \mathrm{Ti}$, and $\mathrm{Nb}$ ) were further broken and distributed homogeneously due to the effect of shear bands.

Interfacial bonding is a key issue of composites. The improvement of interface strength is beneficial to mechanical properties. Intermetallic compounds will be generated in different metal interfaces. In composites, brittle intermetallic compounds formed at the interface seriously affect the overall performance. A large amount of heat is released during the severe plastic deformation, which will lead to the formation of brittle intermetallic compounds. The XRD tests were conducted to check if there was a new phase. The results showed that there were only peaks of the raw metals in the XRD pattern, and no new intermetallics were observed (as shown in Figure 3.)

The orientation maps on the RD-ND plane after the 1st, 2nd, 3rd, and 4th pass are illustrated in Figure 4. Since the severe plastic deformation of the ARB process, an electropolishing treatment should be conducted on the surface of samples before the EBSD test. The EBSD data is collected by an OIM software. In Figure 4, The correspondence between the colors and the orientations is shown in the triangle. $\mathrm{Al}$ grains were initially compressed, gradually elongated, and finally formed a lamellar structure. According to Alizadeh $[32,33]$, typical dislocation cells were generated in the initial stage. With the increasing ARB pass, a lamellar structure forms. The grain size in the ND was decreased gradually.

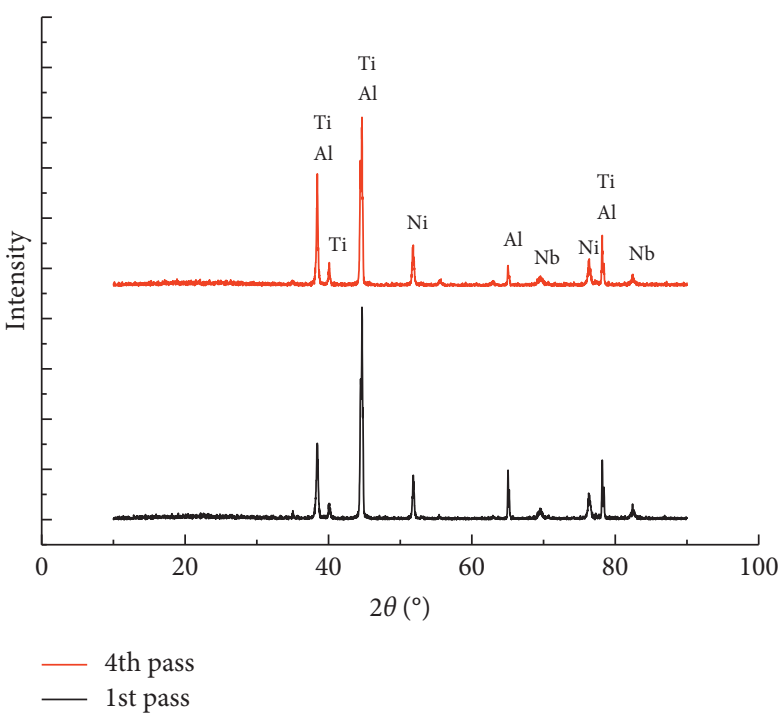

FIgure 3: The XRD pattern of the Al-Nb/Ti/Ni composite.

The grain size in the ND of $\mathrm{Al}$ can be calculated, and results are demonstrated in Figure 5. The range of size distribution was smaller and nearer to $Y$-axis, indicating that the grain size in the ND decreased. Based on the data in Figure 5, the average grain size is calculated, and the results are shown in Figure 6 . The average grain size in the ND decreased significantly. After the fourth pass, the average grain size in the ND was $0.31 \mu \mathrm{m}$. Such a result suggests that rolling deformation plays a critical role in the grain size change in the ND. 


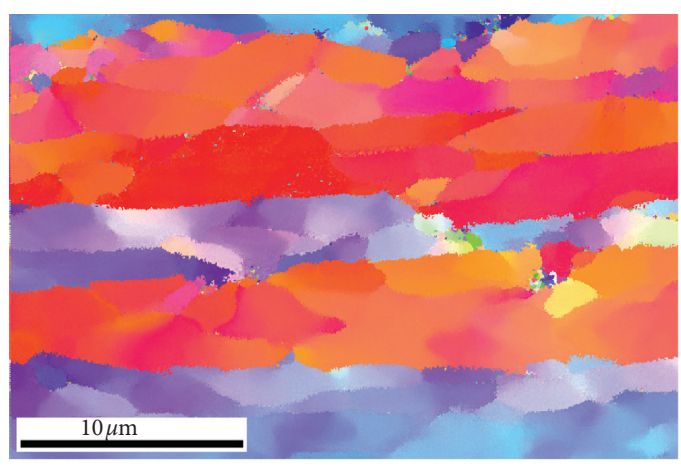

(a)

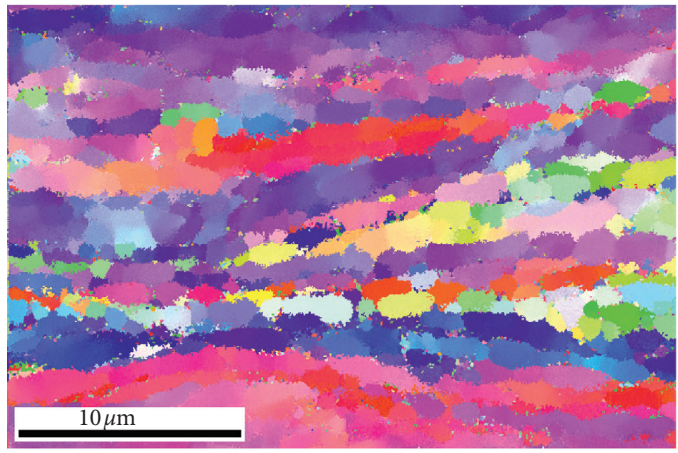

(c)

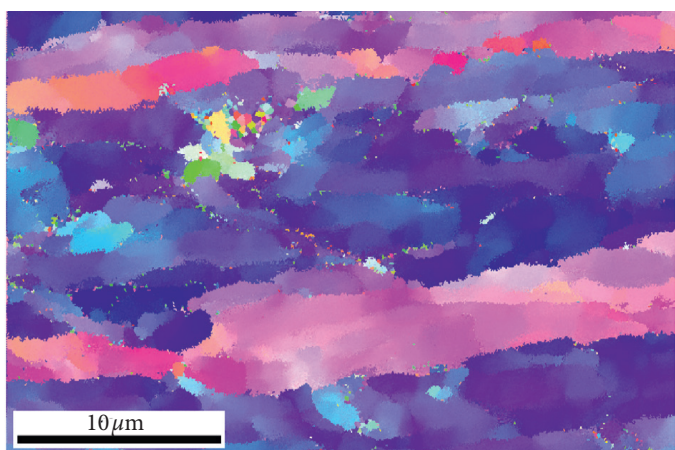

(b)

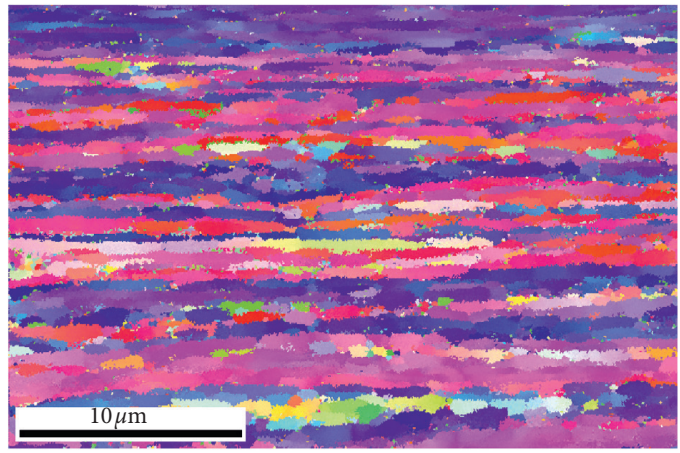

(d)

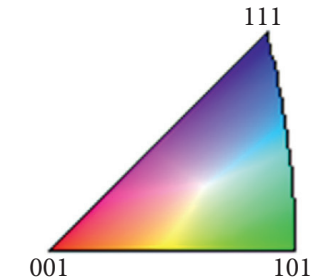

FIGURE 4: The orientation maps of aluminum in the Al-Nb/Ti/Ni composites: (a) the first pass, (b) the second pass, (c) the third pass, and (d) the fourth pass.

Interestingly, we can find that the rate of grain size reduction in the ND is slower gradually in Figure 6. The reasons for this result may be more complicated and related to various factors, such as properties and status of metals. One of the most important reasons is the increase in metal strength and deformation resistance in severe plastic deformation. Due to the effects of work hardening and fine grain strengthening, it is becoming more and more difficult for metals to deform. Consequently, the rate of grain size reduction decreases.

The bright-field TEM micrographs and corresponding selected area diffraction (SAD) patterns on the rolling direction (RD) normal direction (ND) plane are shown in Figure 7. The microstructure of $\mathrm{Al}$ observed in Figure 7 was consistent with that in Figure 4. Moreover, the average grain size calculated in Figure 6 was also confirmed in Figure 7. Obviously, the microstructure of the annealed $\mathrm{Al}$ sheets was changed from equiaxed grains to a lamellar structure during the ARB process. Grains had not been wholly elongated along the rolling direction after the first pass (as shown in Figure 7(a)). Dislocation tangles and dislocation cells are formed in the metal. By increasing ARB passes, $\mathrm{Al}$ grains were gradually elongated along the $\mathrm{RD}$, and then the elongated grains were subdivided into smaller grains by boundaries [32-35].

In Figure $7(\mathrm{a})$, a great number of dislocations were visible. After the second pass, the dislocation density was increased and the grains became finer. The dislocation density was significantly reduced in Figure 7(c), and there were a large number of clear grains with a low density of dislocations (indicated by arrows) among other grains with high dislocation density $[36,37]$. Deformation heat during the ARB process provided energy for the dynamic recovery of aluminum. The temperature of aluminum rose, and then the dynamic recovery occurred in the ARB process. The dynamic recovery easily occurred in metals with high stack fault energy (SFE), such as aluminum and aluminum alloys.

Figure 8 depicts the misorientation angle distributions after different ARB passes. The fraction of HAGBs after the 1 st, 2 nd, 3 rd, and 4 th pass was $0.407,0.34,0.515$, and 0.646 , respectively. In the initial stage, the structure of $\mathrm{Al}$ changed from a recrystallized structure to a lamellar structure, and high-angle grain boundaries were reduced due to the rolling deformation. In the cold-rolling process, the dislocation 


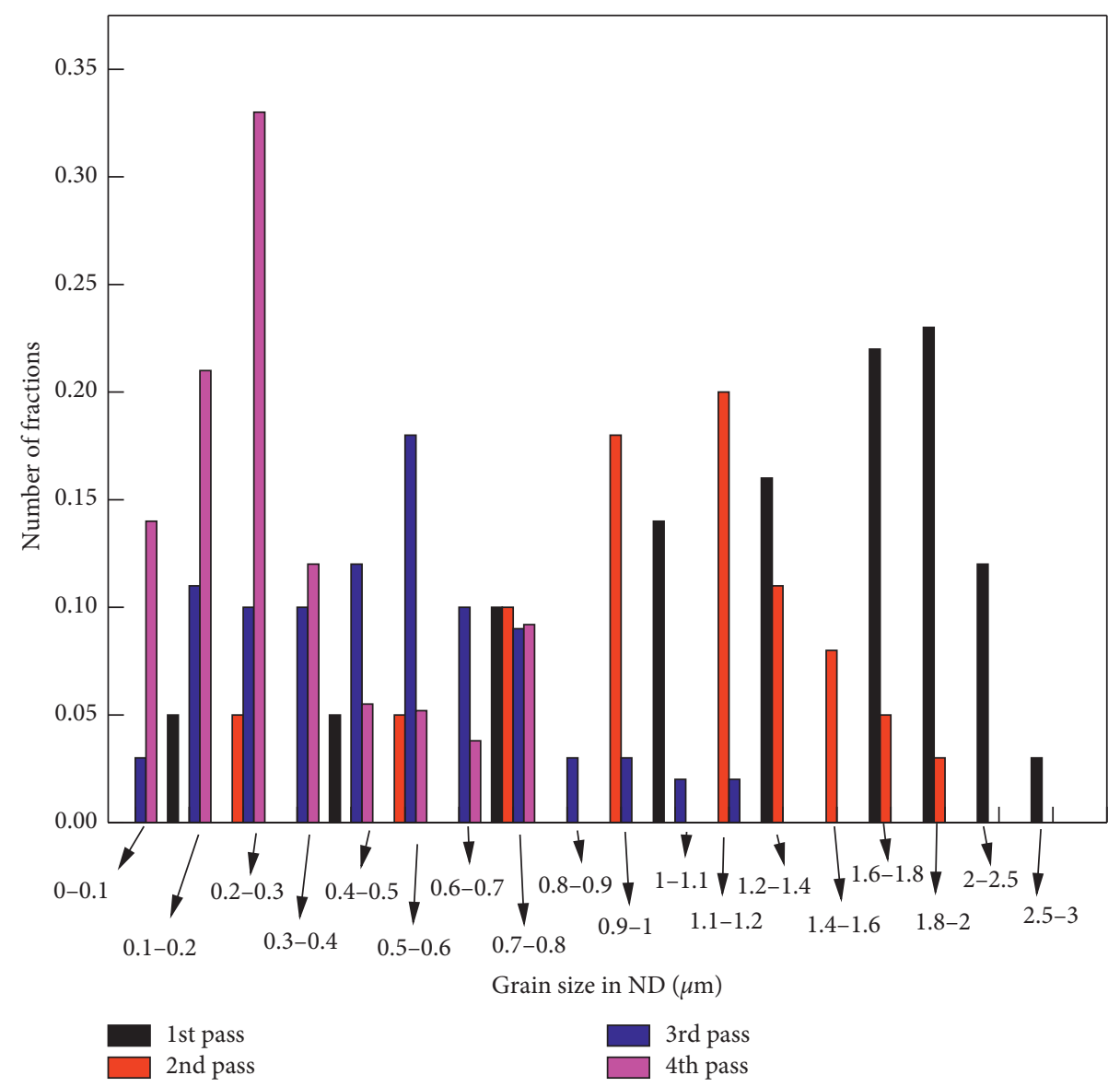

Figure 5: Distribution of $\mathrm{Al}$ grain size in the $\mathrm{ND}$ in the $\mathrm{Al}-\mathrm{Nb} / \mathrm{Ti} / \mathrm{Ni}$ composites.

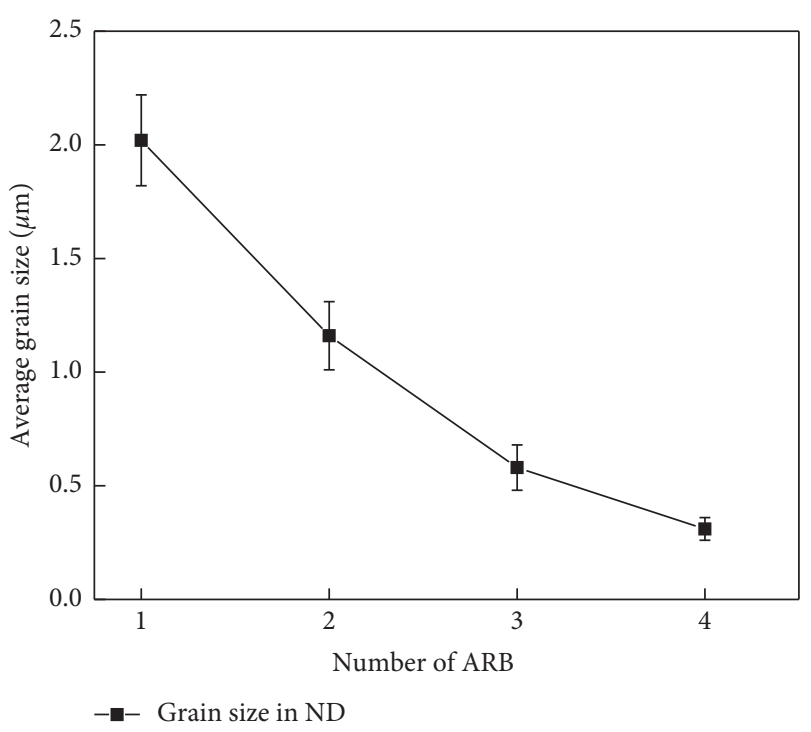

FIGURE 6: Dependence of $\mathrm{Al}$ grain size in the ND on the number of the ARB pass.

density accumulates and the internal distortion energy increases, which causes the initially clear grains to be divided into substructures by a large number of entangled dislocations. These substructures are small-angle grain boundaries resulting in the decrease of HAGBs. After the third pass, the occurrence of dynamic recovery led to an increase in HAGB fraction. At the same time, the elongated grains could be divided by the local shear bands, forming the equiaxed grains, and more HAGBs are generated $[19,24]$. Several investigations [38-40] reported that the grain refinement could form high-angle grain boundaries.

3.2. Texture Evolution. Figure 9 shows the orientation distribution function (ODF) of $\mathrm{Al}$ in the $\mathrm{Al}-\mathrm{Nb} / \mathrm{Ti} / \mathrm{Ni}$ composite. The $\varphi 2=45^{\circ}, 65^{\circ}, 90^{\circ}$ sections are illustrated in the figure. For face-centered cubic (FCC) metals, these sections can contain all the relevant texture components $[19,26,41]$. Figures 9(a)-9(d) show the ODF diagrams of the aluminum after the first, second, third, and fourth pass, respectively, and Figure 9(e) shows the ideal texture composition of Al.

The texture distribution on the RD-ND plane was complex because of the repetition of the rolling process. The texture components obtained in the 1st pass can be characterized as the strong cube $\{001\}<100>$ and weak $S\{123\}$ $<634>$. The Al layer had a strong recrystallization texture due to a full annealing treatment before rolling, and then a small amount of recrystallization texture changed to the rolling texture after the first pass. The recrystallization texture disappeared and completely transformed into the 

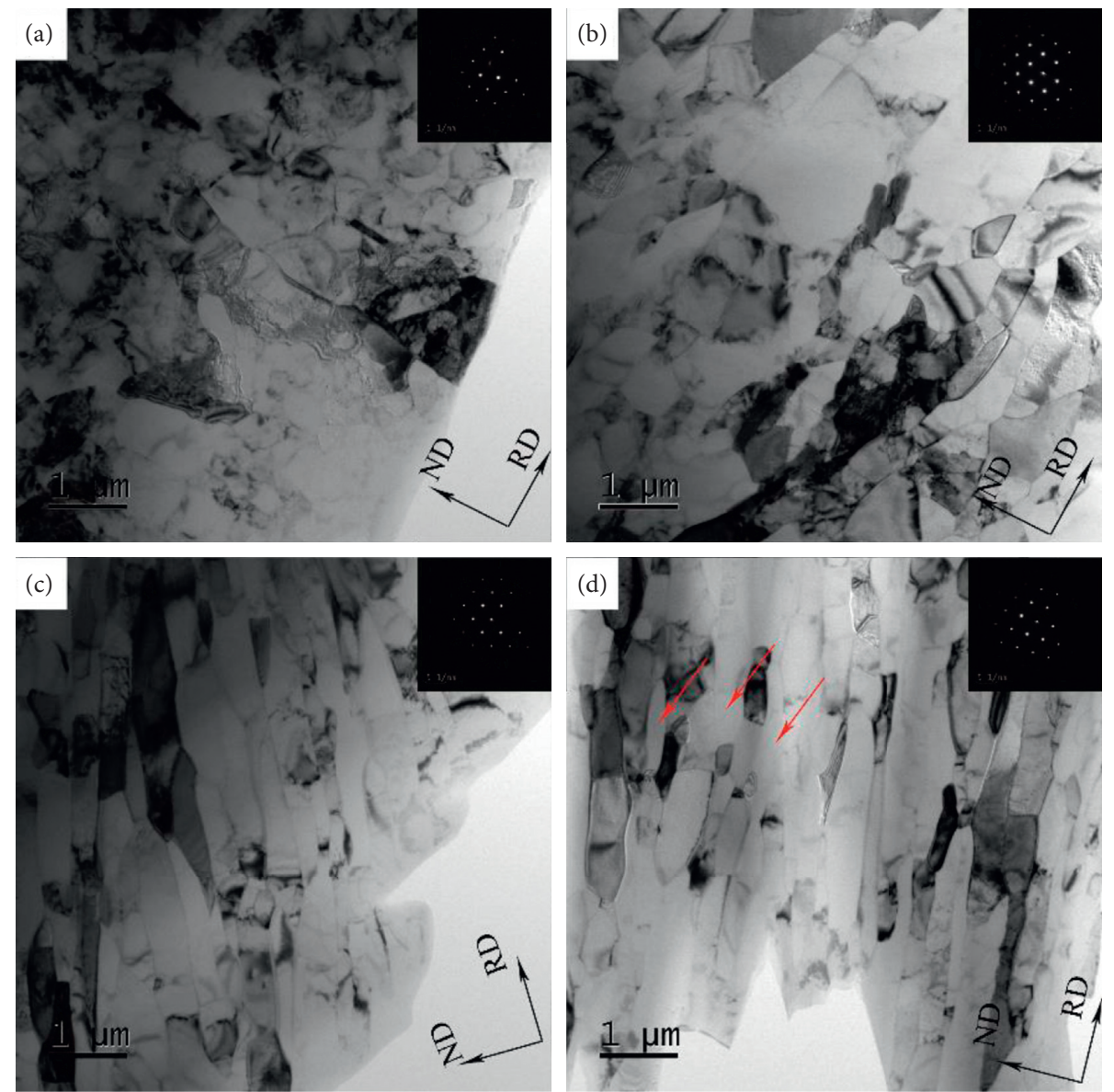

FIGURE 7: TEM micrographs on the RD-ND plane of $\mathrm{Al}$ in the Al-Nb/Ti/Ni composites: (a) 1st pass, (b) 2d pass, (c) 3rd pass, and (d) 4th pass.

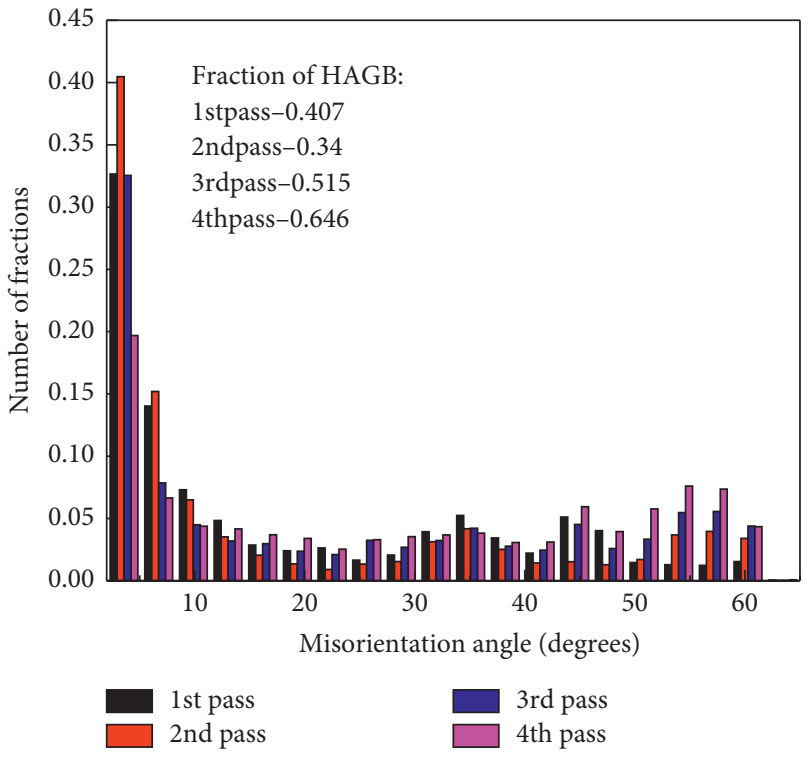

FIGURE 8: Distributions of misorientation angles of the aluminum in the $\mathrm{Al}-\mathrm{Nb} / \mathrm{Ti} / \mathrm{Ni}$ composite.

rolling texture and the shear texture in the third pass. The rolling texture components were composed of Copper $\{112\}$ $<111>$, Dillamore $\{4411\}<11118>, S\{123\}<634>$, and Brass
$\{011\}<211>$, and the shear texture components were Rotated Cube $\{001\}<110>$ and $\{111\} / / N D$ (Figures 9(c) and 9(d)).

This result was different from the texture components in the aluminum ARB process. Pirgazi and Kim $[26,27]$ reported that the main textural components were the Copper $\{112\}<111>$ and Dillamore $\{4411\}<11118>$ components in aluminum alloys ARB process, and no obvious shear texture component was observed. The formation of shear texture component was related to two main factors $[19,26]$. One was the generating of shear bands in the composite. The other was the shear deformation caused by great friction between the sample and the roller. Due to the repetition of the rolling, cutting, and stacking of the ARB, the surface of samples moved to the center in the next pass. Therefore, the shear texture also appeared in the center.

For the cold-rolling process of aluminum or aluminum alloys [24-31], the main rolling texture components were $\beta$-fiber and $\tau$-fiber. Generally, the intensity of $\beta$-fiber and $\tau$-fiber increased with the increasing amount of cold-rolling deformation. Pirgazi et al. [27] reported that the intensity of $\beta$-fiber and $\tau$-fiber increased significantly in the deformation. Kim et al. [26] also observed similar results of the intensity of $\tau$-fiber after four passes of the ARB process.

However, no obvious increase in rolling texture intensity could be seen in the $\mathrm{Al}-\mathrm{Nb} / \mathrm{Ti} / \mathrm{Ni}$ composite (Figure 9). The 

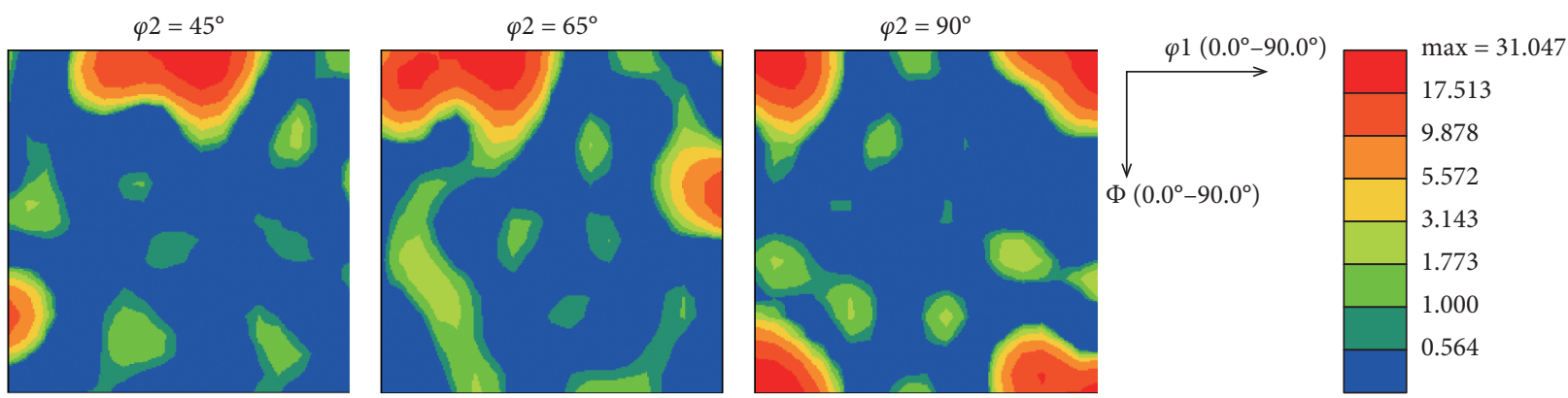

(a)
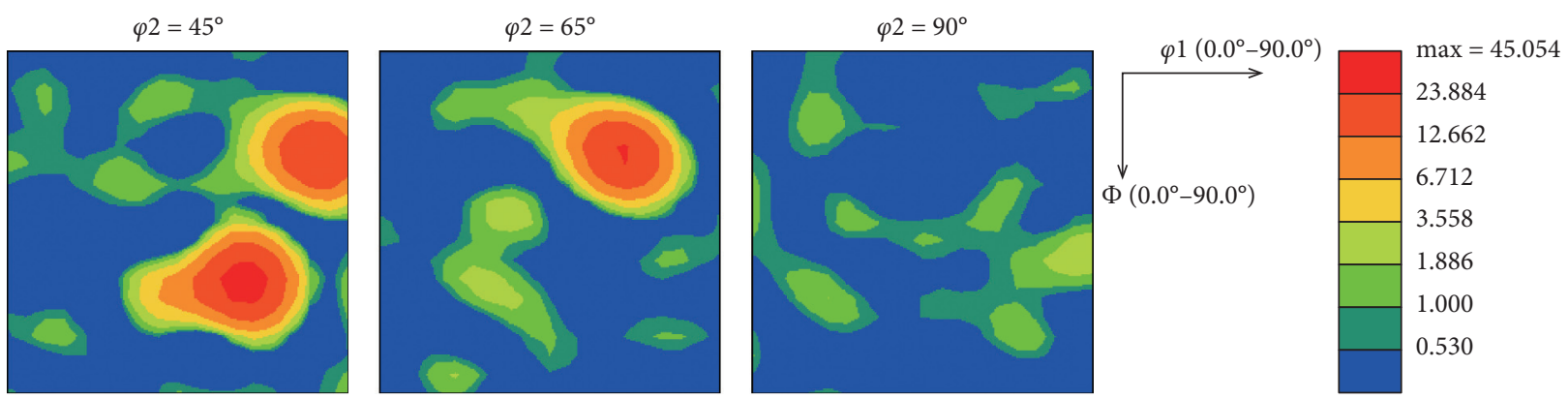

(b)
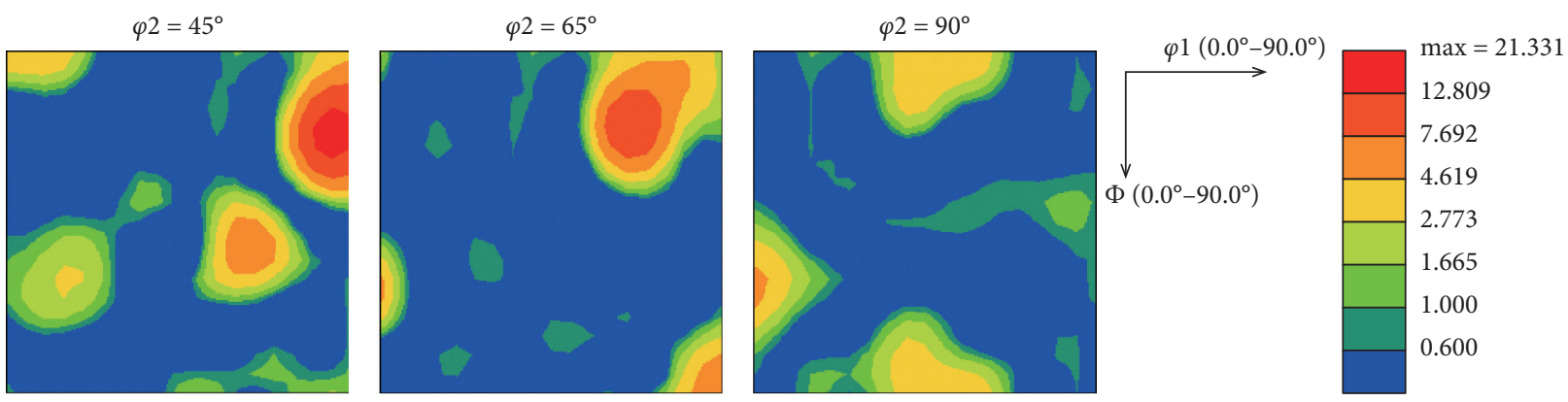

(c)
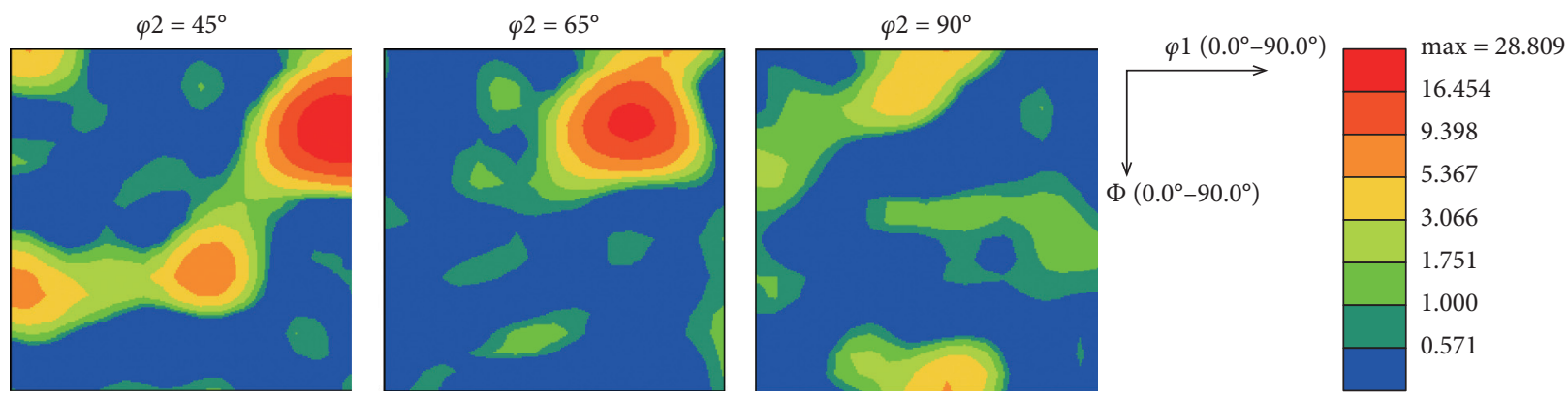

(d)
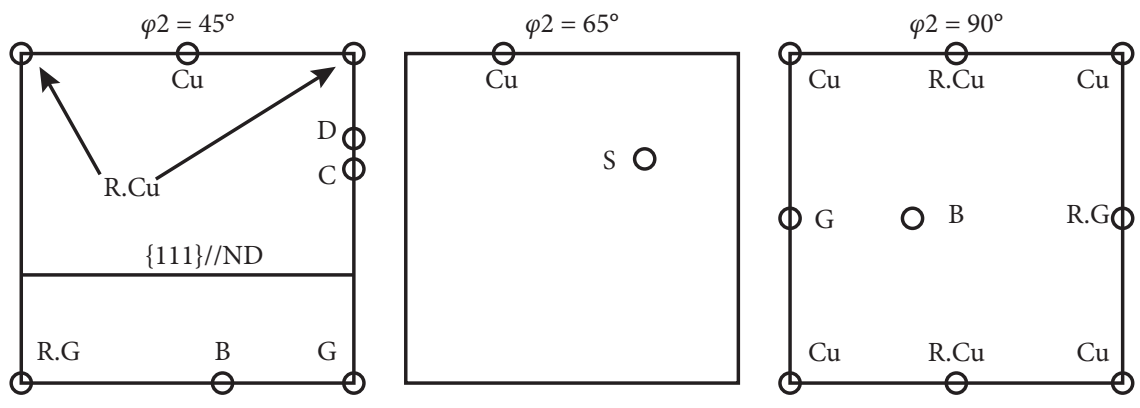

(e)

Figure 9: The ODFs of $\mathrm{Al}$ in the $\mathrm{Al}-\mathrm{Nb} / \mathrm{Ti} / \mathrm{Ni}$ composites: (a) 1st pass, (b) 2nd pass, (c) 3rd pass, (d) 4th pass, and (e) an ideal texture components of Al. Cu: cube; D: dillamore; C: copper; B: brass; G: goss; R.G: rotated goss; R.Cu: rotated cube; S: S. 


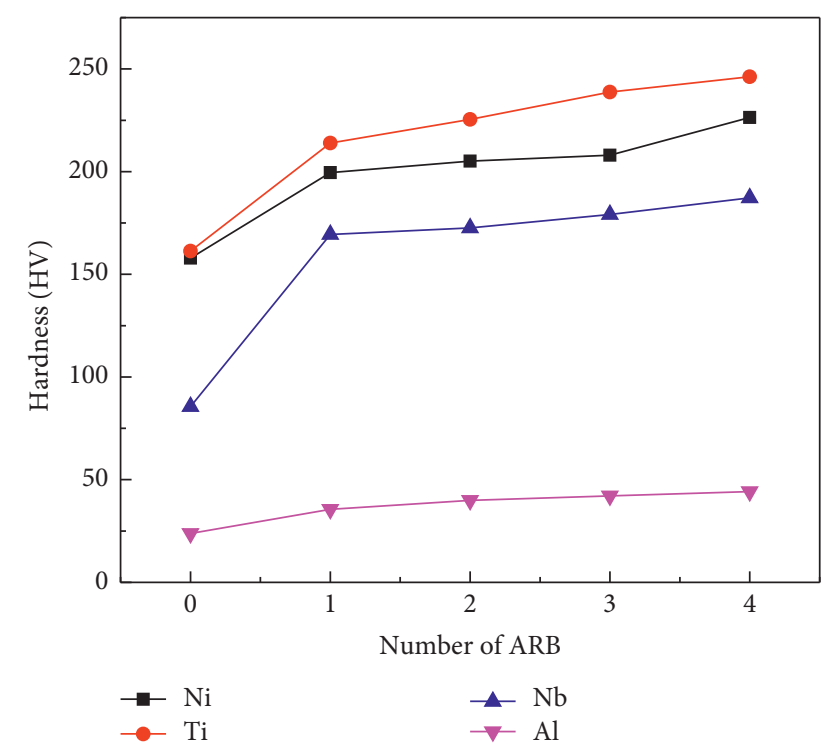

Figure 10: Variation of microhardness after different passes.

reason why the rolling texture intensity is not significantly improved is the effect of the shear bands. Qu et al. [19] found that shear bands led to not only a $15^{\circ}$ deviation of rolling texture from the RD but also a decreasing intensity of rolling texture in aluminum. Chang et al. [15] reported that the shear bands reduced the intensity of rolling texture and $t$ changed the texture orientation in the $\mathrm{Mg} / \mathrm{Al}$ composite. Li et al. [42] observed a similar phenomenon in the $\mathrm{Mg} / \mathrm{Al}$ composite. Furthermore, Toroghinejad et al. [24] showed that the intensity decrease of major texture components could be explained by the continuous recrystallization. Therefore, the dynamic recovery in this ARB process might influence the intensity of rolling texture components.

Figure 10 shows the microhardness variations of the $\mathrm{Al}-\mathrm{Nb} / \mathrm{Ti} / \mathrm{Ni}$ composite. The microhardness of nickel, titanium, niobium, and aluminum was enhanced significantly from $157.9,161.3,85.6$, and $23.8 \mathrm{HV}$ to $199.5,213.9$, 169.4, and $35.6 \mathrm{HV}$, respectively. The rapid increase of microhardness after the first pass was due to the hardening. In the subsequent deformation, the microhardness change was mainly determined by the fine grain strengthening. Due to the dynamic recovery of $\mathrm{Al}$, its microhardness growth rate was less than the other three. Finally, the microhardness of $\mathrm{Ni}, \mathrm{Ti}, \mathrm{Nb}$, and $\mathrm{Al}$ reached 226.4, 246.3, 187.2, and 44.2 HV.

One of the reasons for the increasing hardness in the composite may be the different thermal conductivities between the four metals $[18,43]$. Generally, the temperature of the sample increases due to plastic deformation and the friction between the roller and the sample. Finally, due to the different cooling rates of the four metals, regions with severe thermal stress are generated. According to the thermal expansion coefficients (CTE) of each layer $(\mathrm{Ni}, \mathrm{Ti}, \mathrm{Nb}$, and $\mathrm{Al}$ are $13,8.6,7.1$, and $23 \mu \mathrm{m} / \mathrm{mK}$, respectively), dislocations occur at the interface during deformation, thereby improving the microhardness of the composite.
In addition, we can observe that the microhardness growth rate of $\mathrm{Al}$ is the slowest in Figure 10. It is majorly due to the dynamic recovery in the deformation process, which has a softening effect. At the same time, pure aluminum as a relatively soft metal is difficult to reach a high level of microhardness. Furthermore, niobium has the fastest hardness growth among the other three metals. It is not difficult to find out the reasons through the analysis of the microstructure of composites (Figure 2). The size of $\mathrm{Nb}$ fragments is significantly smaller than that of nickel and titanium, indicating that niobium obtains greater deformation during the ARB process. Therefore, the microhardness of niobium gets a larger increment due to the effect of strain accumulation. In general, the changes in the mechanical properties of the individual metals in the composites are still determined by their own characteristics.

\section{Conclusions}

In summary, the multimetal composite was successfully fabricated by the ARB technology. The following conclusions were obtained.

(1) Nickel, titanium, and niobium fragments were homogeneously distributed in the multimetal composite, and the average size of $\mathrm{Nb}$ fragments was smaller than the other two. In the fourth pass, $\mathrm{Nb}$ fragments with extremely small size were distributed in the $\mathrm{Al}$ matrix. Additionally, Neckings and fractures appeared in the reinforcements $(\mathrm{Ni}, \mathrm{Ti}$, and $\mathrm{Nb}$ ). There was no new intermetallic compound generated in the rolling at room temperature.

(2) In the ARB process, the microstructure of $\mathrm{Al}$ changed from equiaxed grains to a lamellar structure, and the grain size in the ND decreased gradually. Finally, the average grain size in the ND was $0.31 \mu \mathrm{m}$.

(3) After the third pass, the dynamic recovery occurred in the $\mathrm{Al}$ matrix, resulting in an increase of the HGAB fraction and the decrease of the dislocation density. Additionally, the increasing fraction of HGABs was also contributed by shear bands.

(4) After the fourth pass, the Al exhibited a combination texture of rolling texture and shear texture. The rolling texture components were composed of Copper $\{112\}<111>$, Dillamore $\{4411\}<11118>$, S $\{123\}<634>$, and Brass $\{011\}<211>$, and the shear texture components were Rotated Cube $\{001\}<110>$ and $\{111\} / / \mathrm{ND}$.

(5) The microhardness of $\mathrm{Ni}, \mathrm{Ti}, \mathrm{Nb}$, and $\mathrm{Al}$ was improved in the ARB process and finally reached 226.4, $246.3,187.2$, and $44.2 \mathrm{HV}$, respectively.

\section{Data Availability}

The experimental data used to support the findings of this study are included in the article. The other data are available from the corresponding author upon request. 


\section{Conflicts of Interest}

The authors declare that they have no conflicts of interest.

\section{References}

[1] S. V. Prasad and R. Asthana, "Aluminum metal-matrix composites for automotive applications: tribological considerations," Tribology Letters, vol. 17, no. 3, pp. 445-453, 2004.

[2] J. W. Kaczmar and K. Pietrzak, "The production and application of metal matrix composite materials," Journal of Materials Processing Technology, vol. 106, no. 1-3, pp. 58-67, 2000.

[3] W. D. Jeffrey, "Ancient and modern laminated composites-from the great pyramid of gizeh to Y2K," Materials Characterization, vol. 45, no. 4-5, pp. 289-313, 2000.

[4] S. Ozden, R. Ekici, and F. Nair, "Investigation of impact behaviour of aluminium based $\mathrm{SiC}$ particle reinforced metalmatrix composites," Composites Part A: Applied Science and Manufacturing, vol. 38, no. 2, pp. 484-494, 2007.

[5] Y. P. Li, G. P. Zhang, W. Wang, J. Tan, and S. J. Zhu, "On interface strengthening ability in metallic multilayers," Scripta Materialia, vol. 57, no. 2, pp. 117-120, 2007.

[6] Y. Saito, N. Tsuji, H. Utsunomiya, T. Sakai, and R. G. Hong, "Ultra-fine grained bulk aluminum produced by accumulative roll-bonding (ARB) process," Scripta Materialia, vol. 39, no. 9, pp. 1221-1227, 1998.

[7] R. Z. Valiev, R. K. Islamgaliev, and I. V. Alexandrov, "Bulk nanostructured materials from severe plastic deformation," Progress in Materials Science, vol. 45, no. 2, pp. 103-189, 2000.

[8] V. M. Segal, "Equal channel angular extrusion: from macromechanics to structure formation," Materials Science and Engineering A, vol. 271, no. 1-2, pp. 322-333, 1999.

[9] G. Sakai, Z. Horita, and T. G. Langdon, "Grain refinement and superplasticity in an aluminum alloy processed by highpressure torsion," Materials Science and Engineering A, vol. 393, no. 1-2, pp. 344-351, 2005.

[10] N. Tsuji, Y. Ito, Y. Saito, and Y. Minamino, "Strength and ductility of ultrafine grained aluminum and iron produced by ARB and annealing," Scripta Materialia, vol. 47, no. 12, pp. 893-899, 2002.

[11] D. Yang, P. Cizek, P. Hodgson, and C. E. Wen, "Ultrafine equiaxed-grain $\mathrm{Ti} / \mathrm{Al}$ composite produced by accumulative roll bonding," Scripta Materialia, vol. 62, no. 5, pp. 321-324, 2010.

[12] M. Eizadjou, A. Kazemitalachi, H. Daneshmanesh, H. Shakurshahabi, and K. Janghorban, "Investigation of structure and mechanical properties of multi-layered $\mathrm{Al} / \mathrm{Cu}$ composite produced by accumulative roll bonding (ARB) process," Composites Science And Technology, vol. 68, no. 9, pp. 2003-2009, 2008.

[13] A. Mozaffari, M. Hosseini, and H. D. Manesh, "Al/Ni metal intermetallic composite produced by accumulative roll bonding and reaction annealing," Journal of Alloys and Compounds, vol. 509, no. 41, pp. 9938-9945, 2011.

[14] A. Mozaffari, H. Danesh Manesh, and K. Janghorban, "Evaluation of mechanical properties and structure of multilayered $\mathrm{Al} / \mathrm{Ni}$ composites produced by accumulative roll bonding (ARB) process," Journal of Alloys and Compounds, vol. 489, no. 1, pp. 103-109, 2010.

[15] H. Chang, M. Y. Zheng, W. M. Gan, K. Wu, E. Maawad, and H. G. Brokmeier, "Texture evolution of the $\mathrm{Mg} / \mathrm{Al}$ laminated composite fabricated by the accumulative roll bonding," Scripta Materialia, vol. 61, no. 7, pp. 717-720, 2009.
[16] K. Wu, H. Chang, E. Maawad, W. M. Gan, H. G. Brokmeier, and M. Y. Zheng, "Microstructure and mechanical properties of the $\mathrm{Mg} / \mathrm{Al}$ laminated composite fabricated by accumulative roll bonding (ARB)," Materials Science and Engineering A, vol. 527, no. 13-14, pp. 3073-3078, 2010.

[17] H. Chang, M. Y. Zheng, C. Xu, G. D. Fan, H. G. Brokmeier, and $\mathrm{K} . \mathrm{Wu}$, "Microstructure and mechanical properties of the $\mathrm{Mg} / \mathrm{Al}$ multilayer fabricated by accumulative roll bonding (ARB) at ambient temperature," Materials Science and Engineering A, vol. 543, no. 1, pp. 249-256, 2013.

[18] P. D. Motevalli and B. Eghbali, "Microstructure and mechanical properties of Tri-metal $\mathrm{Al} / \mathrm{Ti} / \mathrm{Mg}$ laminated composite processed by accumulative roll bonding," Materials Science and Engineering: A, vol. 628, no. 25, pp. 135-142, 2015.

[19] P. Qu, L. Zhou, and V. L. Acoff, "Deformation textures of aluminum in a multilayered $\mathrm{Ti} / \mathrm{Al} / \mathrm{Nb}$ composite severely deformed by accumulative roll bonding," Materials Characterization, vol. 107, pp. 367-375, 2015.

[20] A. Shabani, M. R. Toroghinejad, and A. Shafyei, "Fabrication of $\mathrm{Al} / \mathrm{Ni} / \mathrm{Cu}$ composite by accumulative roll bonding and electroplating processes and investigation of its microstructure and mechanical properties," Materials Science and Engineering: A, vol. 558, pp. 386-393, 2012.

[21] M. M. Mahdavian, H. Khatami-Hamedani, and H. R. Abedi, "Macrostructure evolution and mechanical properties of accumulative roll bonded $\mathrm{Al} / \mathrm{Cu} / \mathrm{Sn}$ multilayer composite," Journal of Alloys and Compounds, vol. 703, pp. 605-613, 2017.

[22] M. M. Mahdavian, L. Ghalandari, and M. Reihanian, "Accumulative roll bonding of multilayered $\mathrm{Cu} / \mathrm{Zn} / \mathrm{Al}$ : an evaluation of microstructure and mechanical properties," Materials Science and Engineering: A, vol. 579, pp. 99-107, 2013.

[23] N. Ye, X. Ren, and J. Liang, "Microstructure and mechanical properties of the $\mathrm{Ni} / \mathrm{Ti} / \mathrm{Nb}$ multilayer composite manufactured by accumulative pack-roll bonding," Metals, vol. 10, no. 3, p. 354, 2020.

[24] M. R. Toroghinejad, F. Ashrafizadeh, R. Jamaati, M. Hoseini, and J. A. Szpunar, "Textural evolution of nanostructured AA5083 produced by ARB," Materials Science and Engineering A, vol. 556, pp. 351-357, 2012.

[25] M.-y. Zhan, W.-w. Zhang, and D.-t. Zhang, "Production of $\mathrm{Mg}-\mathrm{Al}-\mathrm{Zn}$ magnesium alloy sheets with ultrafine-grain microstructure by accumulative roll-bonding," Transactions of Nonferrous Metals Society of China, vol. 21, no. 5, pp. 991-997, 2011.

[26] H. W. Kim, S. B. Kang, N. Tsuji, and Y. M. Amino, "Deformation textures of AA8011 aluminum alloy sheets severely deformed by accumulative roll bonding," Metallurgical and Materials Transactions A, vol. 36, no. 11, pp. 3151-3163, 2005.

[27] H. Pirgazi, A. Akbarzadeh, R. Petrov, J. Sidor, and L. Kestens, "Texture evolution of AA3003 aluminum alloy sheet produced by accumulative roll bonding," Materials Science and Engineering $A$, vol. 492, no. 1-2, pp. 110-117, 2008.

[28] M. R. T. Roohollahjamaati, M. Hoseini, and J. A. Szpunar, "Texture development in $\mathrm{A} 1 / \mathrm{Al}_{2} \mathrm{O}_{3}$ MMCs produced by anodizing and ARB processes," Materials Science and Engineering $A$, vol. 528, no. 10-11, pp. 3573-3580, 2011.

[29] Y. N. Wang and J. C. Huang, "Texture analysis in hexagonal materials," Materials Chemistry and Physics, vol. 81, no. 1, pp. 11-26, 2003.

[30] S. G. Chowdhury, A. Dutta, B. Ravikumar, and A. Kumar, "Textural evolution during accumulative roll bonding of an Al-Li alloy," Materials Science and Engineering A, vol. 428, no. 1-2, pp. 351-357, 2006. 
[31] M. Raei, M. R. Toroghinejad, R. Jamaati, and J. A. Szpunar, "Effect of ARB process on textural evolution of AA1100 aluminum alloy," Materials Science and Engineering: A, vol. 527, no. 26, pp. 7068-7073, 2010.

[32] M. Alizadeh and E. Salahinejad, "Processing of ultrafinegrained aluminum by cross accumulative roll-bonding," Materials Science and Engineering: A, vol. 595, pp. 131-134, 2014.

[33] S. H. Lee, Y. Saito, T. Sakai et al., "Microstructures and mechanical properties of 6061 aluminum alloy processed by accumulative roll-bonding," Materials Science and Engineering $A$, vol. 325, no. 1-2, pp. 228-235, 2002.

[34] M. Alizadeh and E. Salahinejad, "A comparative study on metal-matrix composites fabricated by conventional and cross accumulative roll-bonding processes," Journal of Alloys and Compounds, vol. 620, pp. 180-184, 2015.

[35] A. H. Yaghtin, E. Salahinejad, and A. Khosravifard, "Processing of nanostructured metallic matrix composites by a modified accumulative roll bonding method with structural and mechanical considerations," International Journal of Minerals, Metallurgy, and Materials, vol. 19, no. 10, pp. 951956, 2012.

[36] M. Hosseini, N. Pardis, H. D. Manesh, M. Abbasi, and D. Kim, "Structural characteristics of $\mathrm{Cu} / \mathrm{Ti}$ bimetal composite produced by accumulative roll-bonding (ARB)," Materials and Design, vol. 113, pp. 128-136, 2016.

[37] K. Edalati and Z. Horita, "High-pressure torsion of pure metals: influence of atomic bond parameters and stacking fault energy on grain size and correlation with hardness," Acta Materialia, vol. 59, no. 17, pp. 6831-6836, 2011.

[38] X. Huang, N. Tsuji, N. Hansen, and Y. Minamino, "Microstructural evolution during accumulative roll-bonding of commercial purity aluminum," Materials Science and Engineering $A$, vol. 340, no. 1-2, pp. 265-271, 2003.

[39] N. Tsuji, T. Toyoda, Y. Minamino et al., "Microstructural change of ultrafine-grained aluminum during high-speed plastic deformation," Materials Science and Engineering A, vol. 350, no. 1-2, pp. 108-116, 2003.

[40] X. Huang, N. Tsuji, N. Hansen, and Y. Minamino, "Microtexture of lamellar structures in Al heavily deformed by accumulative roll-bonding (ARB)," Materials Science Forum, vol. 408-412, pp. 715-720, 2002.

[41] P. Qu, L. Zhou, H. Xu, and V. L. Acoff, "Microtexture development of niobium in a multilayered $\mathrm{Ti} / \mathrm{Al} / \mathrm{Nb}$ composite produced by accumulative roll bonding," Metallurgical and Materials Transactions A, vol. 45, no. 13, pp. 6217-6230, 2014.

[42] M. Li, X. Liu, Y. Liu, M. Zheng, C. Wang, and D. Chen, "Texture evolution and mechanical properties of $\mathrm{Mg} / \mathrm{Al}$ multilayered composite sheets processed by accumulative roll bonding," Acta Metallurgica Sinica, vol. 52, no. 4, pp. 463472, 2016.

[43] R. N. Dehsorkhi, F. Qods, and M. Tajally, "Investigation on microstructure and mechanical properties of Al- $\mathrm{Zn}$ composite during accumulative roll bonding (ARB) process," Materials Science and Engineering: A, vol. 530, pp. 63-72, 2011. 